\title{
The Impact of the Financial Sector on Asset Pricing Tests: Evidence from the Colombo Stock Exchange
}

\author{
Amal Peter Abeysekera \\ Department of Finance, University of Sri Jayewardenepura, Sri Lanka \\ PO Box 10250, Nugegoda, Sri Lanka \\ E-mail: amalabey@sjp.ac.lk \\ P. D. Nimal (Corresponding author) \\ Department of Finance, University of Sri Jayewardenepura, Sri Lanka \\ PO Box 10250, Nugegoda, Sri Lanka \\ Tel: 94-71-70-06713 E-mail:pdnimal@sjp.ac.lk
}

Received: Sep. 20, 2016 Accepted: Oct. 12, $2016 \quad$ Published: December 1, 2016

doi:10.5296/ajfa.v8i2.10056 URL: http://dx.doi.org/10.5296/ajfa.v8i2.10056

\begin{abstract}
This paper aims to identify how the inclusion of financial sector affects the ability of asset pricing models to explain the average stock returns in the CSE. Most of the asset pricing researches, the firms in the financial sector are excluded on the basis that their characteristics and the leverage are notably different than firms in other industries. Therefore the objective of this study is to identify the impact of the inclusion of financial sector on the ability of the Carhart four-factor model to explain the average stock returns in the CSE and to compare its performance with the Capital Asset Pricing Model (CAPM) and the Fama and French three-factor model. The study finds that the four-factor model; incorporating the market premium, size premium, value premium and momentum premium provides a satisfactory explanation of the variation in the cross-section of average stock returns in the CSE, even when the financial sector is included. It is found that the Carhart four-factor model performs better than the CAPM in all scenarios; and that it performs notably better than the Fama and French three-factor model.However, there is no notable difference in the findings either the financial sector is included or not.
\end{abstract}

Keywords: CAPM, Carhart four-factor model, Fama and French three-factor model, Financial sector, Stock Returns

$J E L: G 12, G 13$ 


\section{Introduction}

Empirical asset pricing models attempt to explain the variation in the cross section of average returns via the identification of systematic risk factors. Fama and French (1992) study the impact of several factors, including leverage on security returns of non-financial firms and conclude that size and book-to-market $(\mathrm{B} / \mathrm{M})$ ratios are the strongest factors. Fama and French (1993) propose a three-factor model, which posits that the cross-section of average returns can be explained by the excess market return $\left(R m_{t}-R f_{t}\right)$, a size factor $\left(S M B_{t}\right)$ and a book-to-market $(\mathrm{B} / \mathrm{M})$ factor $\left(H M L_{t}\right)$. Carhart (1997) proposes the addition of a fourth factor termed the momentum factor $\left(W M L_{t}\right)$ to the Fama and French (1993) three-factor model. In these empirically motivated studies it has become a standard practice to exclude financial firms from the sample. The rationale for such exclusion is that financial firms have high leverage, and high leverage may not have the same meaning as it does for non-financial firms; i.e. high leverage for non-financial firms generally translates as "distress".

However, there are some studies that have analyzed the relationship between factors and security returns of financial firms (Barber and Lyon (1997)), Cooper, Jackson and Patterson (2003), Foerster and Sapp (2005) and have produced mix results. As far as Sri Lankan market is concern almost all studies on this theme have been conducted only for non-financial firms though the size of the financial sector is quite large.

Therefore the focus of this paper is not to identify factors that could contribute to the explanation of the variation in the cross-section of average returns but rather to identify the impact of the inclusion of financial sector on the relationship between security returns andrisk factors. Specifically, this study tests the ability of the Carhart (1997) four-factor model to explain the variation in the cross-section of average returns in the CSE with and without the financial sector. Furthermore the performance of the four-factor model is evaluated against the CAPM and the Fama and French (1993) three-factor model, and it is examined whether the inclusion of the financial sector alters the conclusions arrived at when the financial sector was excluded.

The rest of the paper is organized as follows; Section 2 provides a brief review of the literature, Section 3 describes the sample and data and Section 4 deals with the methodology used in the study. Section 5 presents the summary statistics and Section 6 turns to the tests of asset pricing models. Section 7 concludes the paper.

\section{Literature Review}

Barber and Lyon (1997) analyze the relationship between size, B/M and security returns for financial firms. While they agree that high leverage of financial firms may not have the same meaning as for non-financial firms, they argue that there is no reason to expect that size and $\mathrm{B} / \mathrm{M}$ ratios should have different meanings for financial and non-financial firms. The focus of their paper is on comparing the summary characteristics of the returns of both financial and non-financial firms. They use the same approach used by Fama and French (1992) and form portfolios based on size deciles and $\mathrm{B} / \mathrm{M}$ deciles. They document that financial and non-financial firms have very similar return patterns and that both types of firms exhibit a 
significant size and $\mathrm{B} / \mathrm{M}$ premium. Further they report that neither the size premium nor the $\mathrm{B} / \mathrm{M}$ premium statistically differs across financial and non-financial firms.

Cooper, Jackson and Patterson (2003) examine the predictability of the cross-section of stock returns of financial firms by using information contained in fundamental variables of financial firms such as income from derivative usage, loan-loss reserves, earnings and leverage. They conclude that neither size nor $\mathrm{B} / \mathrm{M}$ is important in their sample.

Foerster and Sapp (2005) analyze the impact of excluding financial firms from asset pricing tests in countries with large financial sectors, by comparing results when financial firms are included and excluded. They find that including financial firms in empirical asset pricing tests can impact the corresponding inferences. In their study the inclusion of the financial sector affects the significance of the factors and their corresponding betas, and some models are accepted when financial firms are included but are rejected when they are excluded.

In the Sri Lankan context the research done in the area of empirical asset pricing tests exclude the financial sector (Samarakoon, 1997; Nimal, 1997;Nanayakkara, 2008).Moreover, Abeysekera and Nimal (2016) find that the four-factor model performs better than the CAPM and the three-factor model for non-financial firms listed in the CSE.Therefore it is important to identify the impact the financial sector has in empirical asset pricing tests done with regard to the CSE.

\section{Sample and Data}

The sample period of this study extends from October 1997 to September 2012. All tests are done for the entire population of firms listed in the CSE (including financial firms) and are compared with the results of Abeysekara and Nimal (2016) where the financial firms are excluded. The total number of companies listed in the CSE range from 127 (26 finance) companies in 1998 to 217 (60 finance) companies in 2012 and the number of companies selected each year for the study range from 80 (21 finance)companies to 160 (31 finance) companies that satisfy the selection criteria.Monthly stock returns are calculated under a reinvestment assumption and they include all forms of benefits given to shareholders that are measurable in monetary terms. Following Nimal (2006), monthly stock returns are calculated as percentagereturns incorporating the net effect of capital gains/losses, dividends, stock splits, bonus issues and right issues. Information required in calculating the monthly stock returns are obtained from the CSE. Similar to Pathirawasam and Weerakoon (2008); Anuradha and Nimal (2013) monthly stock returns greater than $+50 \%$ or less than $-50 \%$, are considered as outliers and are removed from the sample. Monthly excess returns are calculated as the returns in excess of the risk-free rate.

The percentage change in the Total Return Index (TRI) is used as a surrogate for the market return. The TRI reflects returns due to both price changes and dividends; it is calculated under the assumption that dividends earned are reinvested in the market. Since the TRI was introduced only in January 2004; the TRI values till October 1997 are obtained by extrapolating the TRI backwards. The monthly risk-free ratesare derived from the 91-days Treasury bill ratesobtained from the Central Bank of Sri Lanka. 


\section{Methodology}

Empirical asset pricing tests require specifying the risk factors (explanatory variables) and the test assets (dependent variables) which are to be used in the regressions. In doing so portfolios are formed to generate the explanatory and dependent variables. The portfolios forming the explanatory variables are referred to as the right-hand side (RHS) portfolios and the portfolios generating the dependent variables are referred to as the left-hand side (LHS) portfolios.

\subsection{Portfolio Formation}

Following the factor mimicking portfolio approach of Fama and French $(1996,2012)$ portfolios are formed based on size and $\mathrm{B} / \mathrm{M}$ ratio; and on size and momentum in order to obtain explanatory returns for the regressions. All portfolios' returns are calculated using excess stock returns.

Company size is measured in terms of market capitalization. Book equity is calculated as the difference between total assets and total liabilities. The $\mathrm{B} / \mathrm{M}$ ratio is calculated at the end of the fiscal year of each company; i.e. the book equity of a company at the end of its fiscal year is divided by its market capitalization on that day. As the financial years of companies listed in the CSE end either in December or March, this generates a series of B/M ratios on the $31^{\text {st }}$ of December for December-end companies and another series of $\mathrm{B} / \mathrm{M}$ ratios on the $31^{\text {st }}$ of March for March-end companies. Following the Fama and French $(1996,2012)$ methodology stocks with negative $\mathrm{B} / \mathrm{M}$ ratios are not considered.

In the present study similar to Fama and French (2012), momentum is represented by the lagged return. Lagged momentum return of a stock is its cumulative excessreturn from $t-11$ to $t-1$. Skipping the sort month in this manner is a standard practice in momentum tests, due to Jegadeesh's (1990) evidence of negative correlation (i.e. reversal rather than continuation) of month-to-month returns. It is to be noted that the first momentum calculation absorbs a year of data; therefore the sample period for the regression is actually 14 years, although data of 15 years are used for the calculations.

The explanatory returns are calculated by forming RHS portfolios from $2 \times 3$ sorts on size and $\mathrm{B} / \mathrm{M}$. Portfolios are formed at the end of September of year $\mathrm{t}$ and the monthly equal-weighted stock returns for each portfolio is calculated from October of year $t$ to September of year $t+1$; after which portfolios are reformed in September of year $t+1$. The CSE requires each company to publish their audited accounts by June for December-end companies and by September for March-end companies. Therefore following Samarakoon (1997) September 31 st is chosen as the portfolio formation date in order to provide a gap between the financial year-end and return calculation period. This is done in order to avoid the 'look-ahead' bias as emphasized by Banz and Breen (1986). Further to be included in a size-B/M portfolio a stock is required to have a return for each of the twelve months following the portfolio formation.

In the $2 \times 3$ sorts on size and B/M; stocks are grouped into two portfolios based on the median market capitalization. Further the same stocks are grouped in to three portfolios based on $\mathrm{B} / \mathrm{M}$ ratio, where the breakpoints are taken as the $30^{\text {th }}$ and $70^{\text {th }}$ percentiles of the $\mathrm{B} / \mathrm{M}$ ratio. 
The intersection of the independent $2 \times 3$ sorts on size and $\mathrm{B} / \mathrm{M}$ produces six portfolios: SG,SN,SV,BG,BN and BV, where $\mathrm{S}$ and $\mathrm{B}$ indicate small and big and $\mathrm{G}, \mathrm{N}$ and $\mathrm{V}$ indicate growth, neutral and value respectively. Growth firms have a lower B/M (below the $30^{\text {th }}$ percentile) and value firms have a higher $\mathrm{B} / \mathrm{M}$ (above the $70^{\text {th }}$ percentile).

The monthly size factor (SMB) is calculated as the difference between the average return on the three small-cap stock portfolios and the three big-cap stock portfolios. The monthly value factor (HML) is calculated as the difference between the average return of the two high $\mathrm{B} / \mathrm{M}$ portfolios (value portfolios) and the average return of the two low $\mathrm{B} / \mathrm{M}$ portfolios (growth portfolios). In order to generate returns to be used for the regression as dependent variables, LHS portfolios are created using $3 \times 3$ sorts on size and $\mathrm{B} / \mathrm{M}$, resulting in 9 portfolios. Given the minute size of the CSE, tertiles are used as the breakpoints; using quartiles or quintiles result in some portfolios having zero stocks.

In order to calculate the momentum factor (WML) another $2 \times 3$ sorts is used where $\mathrm{B} / \mathrm{M}$ is replaced by the lagged return. Since momentum returns are short term (Jegadeesh and Titman, 1993) size-momentum portfolios are formed monthly and the return of the portfolios are calculated for the succeeding month (Fama and French, 2008 and 2012). Therefore to be included in a size-momentum portfolio, a stock is required to have a return for the month following the portfolio formation. All other mechanics of portfolio formation remains the same; thus generating another set of six portfolios: SL,SN,SW,BL,BN and BW, where S and $\mathrm{B}$ indicate small and big, and $\mathrm{L}, \mathrm{N}$ and $\mathrm{W}$ indicate losers, neutral and winners respectively. Losers are firms with a lagged return below the $30^{\text {th }}$ percentile and winners are firms with a lagged return higher than the $70^{\text {th }}$ percentile.

The monthly momentum factor (WML) is calculated as the difference between the average return of the two winners' portfolios and the average return of the two losers' portfolios. A group of LHS portfolios are formed withtertiles as the breakpoints by using $3 \times 3$ sorts on size and momentum. This is done so that another set of regressions could be run using these nine portfolio returns as the dependent variables.

\subsection{Statistical Methods}

In order to evaluate the overall validity of the four-factor model, in its ability to explain the differences of the cross sectional average excess returns of the CSE and to compare its performance relative to the CAPM and the three-factor model; the GRS F-statistic along with its $\mathrm{p}$-value, the average absolute intercept (denoted by $|\mathrm{a}|$ ), the average adjusted $\mathrm{R}^{2}$, the average standard error of the intercepts $[s(a)]$ and the Sharpe ratio for the intercepts [denoted by SR(a)] are reported and analyzed.

The GRS F-statistic is used to test the hypothesis that the regression intercepts for a set of 9 portfolios are statistically indistinguishable from zero (Gibbons, Ross and Shanken, 1989). The SR(a) is the maximum Sharpe ratio for excess returns on the portfolios of the LHS assets contracted to have zero slopes on the RHS returns. In other words it can be termed as the Sharpe ratio for the intercepts (i.e. unexplained average returns) of a model (Fama and French, 2012). Given the above definition for the SR(a) it follows that lower the Sharpe ratio for the 
intercepts better the model is.

As the SR(a) combines information about both the magnitude and the precision of the intercepts into one summary statistic, the average absolute intercept (as a measure of the relative magnitude) and the average $\mathrm{R}^{2}$ and the average standard error of the intercepts (as measures of precision) are also reported separately so that information on the magnitude and the precision of intercepts are not lost.

\section{Summary Statistics}

These summary statistics are intended to provide a preliminary insight in to the nature of the data that has been considered in this study.

\subsection{Explanatory Returns (Factors)/RHS Portfolio Returns}

Given in Table 1 are the average premiums and their standard deviations for the period under consideration. t-Mean is the ratio of the mean to its standard error. The average market premium (i.e. the average difference between the monthly market return and risk-free rate) is $1.17 \%(t=2.00)$. However the market premium is highly volatile compared to the other factors with a standard deviation of $7.58 \%$. The average size premium is positive when financial firms are excluded but is found to be negative when all companies are considered. It is to be noted that in both cases the size premium is minute and insignificant compared to the equity or value premium.In both scenarios the value premium is positive and fairly large. However there hardly appears to be a momentum premium present, with the average WML factor being less than $0.00(t=-0.01)$ when the financial firms are excluded and $0.02(\mathrm{t}=0.08)$ when all companies are considered.

Following Fama and French (2012), Table 1 also presents the average HML and WML factors and the standard deviation for both small-cap and big-cap stocks. When the financial sector is excluded the big-cap stocks have a larger value premium compared to small-cap stocks albeit not very much different from the small-cap stocks. The momentum premium is seen only with big-cap stocks and it is negative for small-cap stocks. When all the sectors of the CSE are considered still the value premiums are larger for big-cap stocks. Again the momentum premium is seen only in the big-cap stocks and is negative for the small-cap stocks.

Table 1. Summary statistics for explanatory variables

\begin{tabular}{|c|c|c|c|c|c|c|c|c|c|c|}
\hline & Rm-Rf & SMB & HML & HML $_{\mathrm{S}}$ & $\mathrm{HML}_{\mathrm{B}}$ & $H_{M} L_{S-B}$ & WML & WML $_{\mathrm{S}}$ & $\mathrm{WML}_{\mathrm{B}}$ & WML $_{S-B}$ \\
\hline \multicolumn{11}{|c|}{ ExcludingFinance } \\
\hline Mean & 1.17 & 0.09 & 0.54 & 0.52 & 0.57 & -0.06 & 0.00 & -0.22 & 0.21 & -0.43 \\
\hline Standar & 7.58 & 2.93 & 3.55 & 4.79 & 4.67 & 6.25 & 4.17 & 5.28 & 4.89 & 5.84 \\
\hline t-Mean & 2.00 & 0.42 & 1.99 & 1.40 & 1.59 & -0.12 & -0.01 & -0.54 & 0.57 & -0.96 \\
\hline \multicolumn{11}{|c|}{ All Companies } \\
\hline Mean & 1.17 & -0.12 & 0.70 & 0.67 & 0.74 & -0.07 & 0.02 & -0.14 & 0.19 & -0.34 \\
\hline Standar & 7.58 & 2.90 & 3.42 & 4.92 & 4.37 & 6.32 & 3.90 & 4.90 & 4.52 & 5.29 \\
\hline t-Mean & 2.00 & -0.53 & 2.67 & 1.75 & 2.20 & -0.15 & 0.08 & -0.38 & 0.55 & -0.82 \\
\hline
\end{tabular}

The section on excluding finance is extracted from Abeysekera and Nimal (2016) for comparison 
purpose.Portfolios are formed at the end of September each year $t$ by sorting stocks into two market-cap and three B/M groups. Big-cap stocks are those stocks above the median market-cap and small-cap stocks are those below the median market cap. The B/M breakpoints are the $30^{\text {th }}$ and $70^{\text {th }}$ percentiles of $\mathrm{B} / \mathrm{M}$. The independent $2 \times 3$ sorts on size and $\mathrm{B} / \mathrm{M}$ produce six portfolios, $\mathrm{SG}, \mathrm{SN}, \mathrm{SV}$, $\mathrm{BG}, \mathrm{BN}$, and $\mathrm{BV}$, where $\mathrm{S}$ and $\mathrm{B}$ indicate small and big and $\mathrm{G}, \mathrm{N}$, and $\mathrm{V}$ indicate growth, neutral, and value (bottom $30 \%$, middle $40 \%$, and top $30 \%$ of $\mathrm{B} / \mathrm{M}$ ) respectively. Monthly returns on the portfolios are calculated from October to the following September.SMB is the equal-weight average of the returns on the three small-cap stock portfolios minus the average of the returns on the three big-cap stock portfolios. The $2 \times 3$ sorts on size and lagged momentum are similar, but the size-momentum portfolios are formed monthly. For portfolios formed at the end of month $t$, the lagged momentum return is a stock's cumulative return for $t-11$ to $t-1$. The independent $2 \times 3$ sorts on size and momentum produce six portfolios, $\mathrm{SL}, \mathrm{SN}, \mathrm{SW}, \mathrm{BL}, \mathrm{BN}$, and $\mathrm{BW}$, where $\mathrm{S}$ and $\mathrm{B}$ indicate small and big and L, N, and $\mathrm{W}$ indicate losers, neutral, and winners (bottom 30\%, middle $40 \%$, and top $30 \%$ of lagged momentum) respectively. All returns are in LKR. Rm-Rf is the return calculated from the Total Return Index (TRI) minus the one-month T-bill rate (derived from the 91-day Treasury bill rate). Size is the market capitalization at the end of September of each year $t$. The book equity is calculated as the difference between total assets and total liabilities. Negative book equity firms are excluded. The $\mathrm{B} / \mathrm{M}$ ratio used to form portfolios in September of year $t$ is the book common equity for the fiscal year ending in March (December) of year $t(t-1)$ divided by the market equity on the same day. The t-Mean is the ratio of the mean to its standard error. Value-growth returns for small-cap and big-cap stocks as well as winner-loser returns for small-cap and big-cap stocks are presented. $\mathrm{HML}_{\mathrm{S}}$ $=\mathrm{SV}-\mathrm{SG}$ and $\mathrm{HML}_{\mathrm{B}}=\mathrm{BV}-\mathrm{BG}$, and $\mathrm{HML}$ is the equal-weight average of $\mathrm{HML}_{\mathrm{S}}$ and $\mathrm{HML}_{\mathrm{B}} . \mathrm{WML}_{\mathrm{S}}=$ $\mathrm{SW}-\mathrm{SL}$ and $\mathrm{WML}_{\mathrm{B}}=\mathrm{BW}-\mathrm{BL}$, and $\mathrm{WML}$ is the equal-weight average of $\mathrm{WML}_{\mathrm{S}}$ and $\mathrm{WML}_{\mathrm{B}}$. $\mathrm{HML}_{\mathrm{S}-\mathrm{B}}$ $\left(\mathrm{WML}_{\mathrm{S}-\mathrm{B}}\right)$ is the difference between $\mathrm{HML}_{\mathrm{S}}$ and $\mathrm{HML}_{\mathrm{B}}\left(\mathrm{WML}_{\mathrm{S}}\right.$ and $\left.\mathrm{WML}_{\mathrm{B}}\right)$.

These results are markedly different with the findings of Fama and French (2012) with regard to developed markets, where the small-cap stocks were found to drive both the value and momentum premiums.

\subsection{Dependent Variables/LHS Excess Portfolio Returns}

When portfolios are formed on size and $\mathrm{B} / \mathrm{M}$ ratios, the standard size effect (i.e. smaller firms having a larger average return) is not to be seen (Table 2), and there appears to be no persistent pattern in the size effect. Although traces of a reverse size effect can be seen, it is indisputably seen only in the neutral stocks when the financial sector is excluded $(0.85,0.89$, and 0.91). There is a value pattern in all size groups as the theory predicts (Fama and French, 1992, 1996, 2012); that is the average excess returns increase as you move from left to right in the size-B/M matrices. Further the spread in value versus growth average returns is highest for the big-cap stocks; i.e. $0.99 \%(=1.61 \%-0.62 \%)$ when financial firms are excluded and $0.95 \%(=1.67 \%-0.72 \%)$ when all companies are considered. 
Table 2. Summary statistics for the 9 size-B/M portfolios' average excess returns

\begin{tabular}{|c|c|c|c|c|c|c|c|}
\hline \multicolumn{8}{|c|}{ Book-to-Market Equity (Tertiles) } \\
\hline Size & 1 & 2 & 3 & & 1 & 2 & 3 \\
\hline & \multicolumn{3}{|c|}{ Mean Excess Returns } & & \multicolumn{3}{|c|}{ Standard Deviation } \\
\hline \multicolumn{8}{|c|}{ Excluding Finance } \\
\hline 1 & 0.81 & 0.85 & 1.18 & 1 & 9.06 & 7.54 & 7.66 \\
\hline 2 & 0.11 & 0.89 & 0.98 & 2 & 8.96 & 7.74 & 8.36 \\
\hline 3 & 0.62 & 0.91 & 1.61 & 3 & 6.48 & 7.59 & 9.25 \\
\hline \multicolumn{8}{|c|}{ All Companies } \\
\hline 1 & 0.43 & 0.90 & 1.11 & 1 & 8.99 & 7.75 & 7.81 \\
\hline 2 & 0.11 & 0.98 & 0.98 & 2 & 8.34 & 7.72 & 8.18 \\
\hline 3 & 0.72 & 0.87 & 1.67 & 3 & 6.53 & 7.53 & 9.02 \\
\hline
\end{tabular}

The section on excluding finance is extracted from Abeysekera and Nimal (2016) for comparison purpose. At the end of September of each year, size-B/M portfolios are constructed using tertiles as the breakpoints. The intersections of the $3 \times 3$ independent size and $\mathrm{B} / \mathrm{M}$ sorts produce 9 size- $\mathrm{B} / \mathrm{M}$ portfolios.

Table 3. Summary statistics for the 9 size-momentum portfolios' average excess returns

\begin{tabular}{|c|c|c|c|c|c|c|c|}
\hline \multicolumn{8}{|c|}{ Lagged Return (Tertiles) } \\
\hline Size & 1 & 2 & 3 & & 1 & 2 & 3 \\
\hline & \multicolumn{3}{|c|}{ Mean Excess Returns } & & \multicolumn{3}{|c|}{ Standard Deviation } \\
\hline \multicolumn{8}{|c|}{ Excluding Finance } \\
\hline 1 & 1.06 & 1.03 & 0.39 & 1 & 8.73 & 8.10 & 7.98 \\
\hline 2 & 0.52 & 0.96 & 0.76 & 2 & 8.86 & 8.10 & 8.20 \\
\hline 3 & 0.61 & 0.78 & 1.03 & 3 & 8.12 & 7.12 & 7.23 \\
\hline \multicolumn{8}{|c|}{ All Companies } \\
\hline 1 & 0.93 & 0.91 & 0.53 & 1 & 8.90 & 8.18 & 8.04 \\
\hline 2 & 0.57 & 1.02 & 0.60 & 2 & 8.78 & 8.01 & 7.82 \\
\hline 3 & 0.63 & 0.94 & 1.08 & 3 & 8.11 & 7.29 & 7.28 \\
\hline
\end{tabular}

The section on excluding finance is extracted from Abeysekera and Nimal (2016) for comparison purpose. The $3 \times 3$ sorts on size and momentum use the same breakpoint conventions as the size-B/M sorts, except that the size-momentum portfolios are formed monthly. The intersections of the independent $3 \times 3$ size and momentum sorts produce 9 size-momentum portfolios.

For both scenarios shown in Table 3, where portfolios are formed on size and momentum, the momentum pattern prevails in big-cap companies; i.e. when you move from left (last year's losers) to right (last year's winners) the average return increases. However there is a reversal of the momentum pattern for small-cap companies, suggesting a 'contrarian' pattern with the average return decreasing when moving from left to right. In both scenarios the medium-cap firms show a momentum pattern and a reversal when moving from left to right. The spread in momentum average returns is highest for the small-cap stocks when financial firms are excluded and it is highest for the big-cap stocks when all companies are considered.

\section{Asset Pricing Tests}


The regressions run for the four-factor model (not reported) all show a clear size, value and momentum pattern on the coefficients when the financial sector is both excluded and included. Further in both scenarios most of the intercepts were statistically insignificant while most coefficients were statistically significant.

Table 4. Summary statistics for regressions to explain excess returns on the 9 size-B/M portfolios

\begin{tabular}{lcccccc}
\hline & \multicolumn{2}{c}{ GRS test } & $|\mathbf{a}|$ & $\mathbf{R}^{2}$ & $\boldsymbol{s}(\boldsymbol{a})$ & $\mathbf{S R}(\mathbf{a}$ \\
\cline { 2 - 3 } & F-stat & $\mathbf{p}$ & & & & \\
\hline Excluding Finance & & & & & & \\
CAPM & $6.64 *$ & 0.00 & 0.29 & 0.67 & 0.11 & 0.62 \\
Three-Factor & 1.04 & 0.41 & 0.30 & 0.75 & 0.08 & 0.25 \\
Four-Factor & 0.81 & 0.61 & 0.30 & 0.74 & 0.09 & 0.22 \\
All Companies & & & & & & \\
CAPM & $7.54 *$ & 0.00 & 0.31 & 0.71 & 0.14 & 0.66 \\
Three-Factor & 0.77 & 0.64 & 0.24 & 0.80 & 0.08 & 0.21 \\
Four-Factor & 0.76 & 0.66 & 0.23 & 0.81 & 0.08 & 0.21 \\
\hline
\end{tabular}

The section on excluding finance is extracted from Abeysekera and Nimal (2016) for comparison purpose. The regressions use the CAPM, three-factor and four-factor models to explain the returns on portfolios formed on size and B/M. The GRS F-statistic tests whether all intercepts in a set of $9(3 \times 3)$ regressions are zero; $|\mathrm{a}|$ is the average absolute intercept for a set of regressions; $s(a)$ is the average standard error of the intercepts; $\mathrm{R}^{2}$ is the average adjusted $\mathrm{R}^{2}$ and $\mathrm{SR}(\mathrm{a})$ is the Sharpe ratio for the intercepts.

Given in Table 4 are the summary statistics for the regressions of the 9 size-B/M portfolios. As the GRS F-statistics for the CAPM regressions are 6.64 and 7.54 when financial firms are excluded and included respectively, and as they are far into the right tail of the relevant F-distribution, the CAPM is rejected. However when shifting from CAPM to the three-factor model or the four-factor model there is a large drop in the GRS F-statistic and the p-value increases. Therefore the null hypothesis stating that all regression intercepts are statistically equal to zero is not rejected, i.e. the three-factor model and four-factor model are accepted under both scenarios.

Further when moving from CAPM to the three-factor and four-factor model, all other summary statistics mark a clear improvement implying that the three-factor and four-factor model capture the cross section of average returns notably better than the CAPM. However, the four-factor model does not perform extraordinarily better than the three-factor model.

When portfolios are formed on size and momentum (Table 5), the results are different from the size-B/M portfolios in two aspects. Firstly, all three models are to be accepted based on the GRS F-test, as the p-values of the respective F-statistics are higher than 0.05. Secondly, the four-factor model turns out to be indisputably the superior model compared to both the CAPM and the three-factor model, as the GRS F-statistic is clearly lower for the four-factor model and its p-value is higher than the other two models. Further the adjusted $R^{2}$ and SR(a) 
improve in favor of the four-factor model when moving from CAPM and the three-factor model to the four-factor model.

Table 5. Summary statistics for regressions to explain excess returns on the 9 size-momentum portfolios

\begin{tabular}{lcccccc}
\hline & \multicolumn{2}{c}{ GRS test } & $|\mathbf{a}|$ & $\mathbf{R}^{2}$ & $\boldsymbol{s}(\boldsymbol{a})$ & $\mathbf{S R ( a )}$ \\
\cline { 2 - 4 } & F-stat & $\mathbf{p}$ & & & & \\
\hline Excluding Finance & & & & & & \\
CAPM & 1.36 & 0.21 & 0.24 & 0.66 & 0.09 & 0.28 \\
Three-Factor & 1.18 & 0.31 & 0.38 & 0.72 & 0.08 & 0.27 \\
Four-Factor & 0.83 & 0.59 & 0.37 & 0.76 & 0.09 & 0.22 \\
All Companies & & & & & & \\
CAPM & 1.25 & 0.27 & 0.25 & 0.70 & 0.07 & 0.27 \\
Three-Factor & 0.86 & 0.56 & 0.30 & 0.78 & 0.08 & 0.23 \\
Four-Factor & 0.77 & 0.64 & 0.29 & 0.81 & 0.07 & 0.21 \\
\hline
\end{tabular}

The section on excluding finance is extracted from Abeysekera and Nimal (2016) for comparison purpose. The regressions use the CAPM, three-factor and four-factor models to explain the returns on portfolios formed on size and momentum. The GRS F-statistic tests whether all intercepts in a set of 9 $(3 \times 3)$ regressions are zero; $|\mathrm{a}|$ is the average absolute intercept for a set of regressions; $s(a)$ is the average standard error of the intercepts; $R^{2}$ is the average adjusted $R^{2}$ and $S R(a)$ is the Sharpe ratio for the intercepts.

\section{Summary and Conclusions}

This study investigates whether the inclusion of the financial sector would have any bearing on the inferences drawn from asset pricing tests done with regard to the CSE. It uses monthly stock return data from October 1997 to September 2012, and all tests are done for a sample excluding the financial sector as well as for the entire population of firms listed in the CSE (including the financial sector). The factor mimicking portfolio approach of Fama and French $(1996,2012)$ is applied in this study; portfolios are formed based on size and B/M, as well as on size and momentum. The study focuses largely on the Carhart (1997) four-factor model. In order to test the ability of the four-factor model in explaining the average stock returns and to evaluate its performance in comparison with the CAPM and the three-factor model; the adjusted $\mathrm{R}^{2}$, GRS F-test and the Sharpe ratio for the intercepts are used.

The study finds that the inclusion of the financial sector does not alter the conclusions arrived at when the financial sector was excluded. Clear size, value and momentum patterns were seen when observing the loadings or coefficients generated via the regressions excluding and including the financial sector. Further most of the coefficients were statistically significant and most of the intercepts were statistically insignificant. These results strengthen Barber and Lyon's (1997) findings where they conclude that size and B/M ratios have similar meanings for both financial and non-financial firms. The four-factor model is not rejected in either scenario but is found to perform notably better than the CAPM and three-factor model in the size-momentum portfolios. However, the results of the current study contrast with Foerster 
and Sapp (2005), who conclude that the inclusion of financial firms affect the inferences drawn from asset pricing tests. In conclusion with regard to the CSE, it can be said that including the financial sector does not alter the findings of empirical asset pricing tests done by excluding them.

\section{References}

Abeysekera, A. P.,\&Nimal, P. D. (2016). The four factor model and stock returns: evidence from Sri Lanka, Afro-Asian Journal of Finance and Accounting (forth coming).

Anuradha, P. A. N. S.,\& Nimal, P. D.(2013). Momentum in stock returns: evidence from Sri Lanka. In: Proceedings of the Annual Research Symposium. Colombo,University of Colombo.

Barber, B.,\& Lyon, J. (2007). Form size, book-to-market and security returns: a hold-out sample of financial firms. Journal of Finance,52(2), 875-883.http://dx.doi.org/10.1111/j.1540-6261.1997.tb04826.x

Carhart, M. M. (1997). On persistence in mutual fund performance. Journal of Finance,52(1), 57-82.http://dx.doi.org/10.1111/j.1540-6261.1997.tb03808.x

Cooper, M.J., Jackson, W. E.,\&Patterson, G.A. (2003). Evidence of predictability in the cross-section of bank stock returns. Journal of Banking and Finance, 27, 817-850.http://dx.doi.org/10.1016/S0378-4266(01)00263-1

Fama, E. F.,\& French, K. R. (1992). The cross-section of expected stock returns. Journal of Finance,47(2), 427-65.http://dx.doi.org/10.1111/j.1540-6261.1992.tb04398.x

Fama, E. F.,\& French, K. R. (1993). Common risk factors in the returns on stocks and bonds. Journal of FinancialEconomics,33(1), 2-56.http://dx.doi.org/10.1016/0304-405X(93)90023-5

Fama, E. F.,\& French, K. R. (1996). Multifactor explanations of asset pricing anomalies. Journal of Finance,51(1), 55-84.http://dx.doi.org/10.1111/j.1540-6261.1996.tb05202.x

Fama, E. F.,\& French, K. R.(2012). Size, value and momentum in international stock returns. Journal of Financial Economics,105(3), 457-72.http://dx.doi.org/10.1016/j.jfineco.2012.05.011

Foerster, S.R.,\&Sapp, S. G. (2005). Valuation of financial versus non-financial firms:a global perspective. Journal of International Financial Markets, Institutions and Money,15, 1-20.http://dx.doi.org/10.1016/j.intfin.2004.01.003

Gibbons, M. R., Ross, S. A.,\& Shanken, J. (1989). A test of the efficiency of a given portfolio. Econometrica,57(5), 1121-1152.http://dx.doi.org/10.2307/1913625

Jegadeesh, N.,\& Titman, S. (1993). Returns to buying winners and selling losers. Journal of Finance,48(1), 65-91.http://dx.doi.org/10.1111/j.1540-6261.1993.tb04702.x

Nanayakkara, N. S. (2008). Three factor asset pricing model: explaining cross section of stock returns in Sri Lankan stock market. In:Proceedings of Fifth International Conference of 
Business Management. Sri Lanka, University of Sri Jayewardenepura. 57-66.

Nimal, P. D.(1997). Relationship between stock returns and selected fundamental variables: evidence from Sri Lanka. Sri Lankan Journal of Management, 2(3), 268-86.

Nimal, P. D. (2006). Empirical Analysis of the Capital Asset Pricing Model, University of Shiga, Japan: Ph.D Thesis.

Pathirawasam, C.,\& Weerakoon Banda, Y.K.(2008). Profitability of momentum and contrarian strategies in the Colombo stock exchange. In: Proceedings of Fifth International Conference of Business Management. Sri Lanka,University of Sri Jayewardenepura. 27-31.

Samarakoon, L. P. (1997). The cross-section of expected stock returns in Sri Lanka. Sri Lankan Journal of Management, 2(3), 234-50. 